\title{
ПРОБЛЕМА ВОСПАЛИТЕЛЬНЫХ ЗАБОЛЕВАНИЙ ОРГАНОВ МАЛОГО ТАЗА, КАК УГРОЗА РЕПРОДУКТИВНОГО ЗДОРОВЬЯ ЖЕНЩИН ХХІ ВЕКА: РОЛЬ ИППП В ИХ ВОЗНИКНОВЕНИИ
}

THE PROBLEM OF INFLAMMATORY DISEASES OF THE PELVIS ORGANS AS A THREAT TO THE REPRODUCTIVE HEALTH OF WOMEN OF THE XXI CENTURY: ROLE OF STIS IN THEIR OCCURRENCE

\section{Leshcheva I. Korotkih}

Summary. At present, gynecological diseases, in particular, inflammatory diseases of the pelvic organs are growing steadily all over the world. Mostly this pathology affects women of reproductive age. In most cases, sexually transmitted infections play a key role in their occurrence, which today pose a threat to the reproductive health of women. It is worth noting that the clinical picture of inflammatory diseases has changed: there has been an increase in erased forms of the disease, which causes difficulties in early detection, diagnosis, and treatment. And this leads to infertility, ectopic pregnancy, habitual miscarriage, having a negative impact on the quality of a woman's health.

Keywords: reproductive health of women, inflammatory diseases of the pelvic organs, sexually transmitted infections, vaginal microflora, diagnostics, screening.

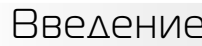

охранение репродуктивного потенциала женщин в настоящее время является одной из основных задач, стоящих перед акушерами-гинекологами всех стран мира [1]. За последние годы заметна тенденция снижения рождаемости и увеличения смертности. Стоит отметить, что на сегодняшний день произошел значительный рост гинекологических заболеваний таких как, миома матки, бесплодие, эндометриоз, дисгормональные заболевания, онкологические заболевания женской репродуктивной системы. Среди всех гинекологических заболеваний, лидирующее место занимают воспалительные заболевания органов малого таза (ВЗОМТ). По данным литературных источников, данная патология встречается в 50\% случаев на амбу-
Лещева Мария Юрьевна

Аспирант, ФГБОУ ВО «Воронежский государственный медицинский университет им. Н.Н. Бурденко» pantera7695@mail.ru

Коротких Ирина Николаевна

Д.м.н., професссор, ФГБОУ ВО «Воронежский государственный медицинский университет им. Н.Н. Бурденко» korotkih_1950@mail.ru

Аннотация. В настоящее время во всем мире неуклонно происходит рост гинекологических заболеваний, в частности, воспалительных заболеваний органов малого таза. Преимущественно данная патология поражает женщин репродуктивного возраста. В большинстве случаев в их возникновении ключевую роль играют инфекции передаваемые половым путем, которые на сегодняшний день составляют угрозу для репродуктивного здоровья женщины. Стоит отметить тот факт, что клиническая картина воспалительных заболеваний изменилась: произошло увеличение стертых форм заболевания, что вызывает сложности ранней выявляемости, диагностики, лечения. А это приводит к бесплодию, внематочной беременности, привычному невынашиванию, оказывая негативное влияние на качество здоровья жизни женщины.

Ключевые слова: репродуктивное здоровье женщины, воспалительные заболевания органов малого таза, инфекции передаваемые половым путем, микрофлора влагалища, диагностика, скрининг.

латорных приемах в женских консультациях и при госпитализации [2]. С каждым годом неуклонно отмечается рост ВЗОМТ у женщин, которые заболели впервые. С 2011 года на 13\% увеличился рост воспалительных заболеваний органов малого таза у женщин репродуктивного возраста, на 25\% у женщин применяющих средства контрацепции [3].

\section{Актуальность проблемы воспалите^ьных заболеваний \\ органов малого таза}

В нашей стране В3ОМТ у женщин репродуктивного возраста (18-45 лет) занимают лидирующее место среди всей гинекологической патологии. При этом около $60 \%$-амбулаторные случаи, а $40 \%$ выявленные в ста- 
ционаре [4]. В последнее время замечен рост воспалительных заболеваний органов малого таза, большая часть из них требует срочного оперативного вмешательства [5]. Анализируя статьи зарубежных авторов, В США ВЗОМТ являются наиболее частой гинекологической причиной госпитализации, на которую приходится 18 случаев из 10000 зарегистрированных выписанных из больниц. Однако, поскольку большинство В3ОМТ протекает бессимптомно, эта цифра недооценивает истинную распространенность. Примерный маркер В3ОМТ в странах с ограниченными ресурсами может быть получен из зарегистрированных показателей госпитализации, где на него приходится от 17\% до 40\% гинекологических госпитализаций в странах Африки к югу от Сахары, от 15\% до 37\% в Юго-Восточной Азии и от $3 \%$ до $10 \%$ в Индии [6].

Воспалительные заболевания органов малого таза могут быть представлены как одной нозоологической структурой, так и в совокупности (сальпингит, сальпингоофорит, эндометрит, параметрит, тазовый перитонит). Акушеры-гинекологи выделяют несколько типов классификаций ВЗОМТ: в зависимости от этиологического агента, по локализации процесса, по характеру клинического течения [7].

\section{Факторы, способствуюшие развитию ВЗОМТ}

На сегодняшний день существует огромное количество факторов, которые способствуют развитию воспалительных заболеваний органов малого таза. Прежде всего, это особенности сексуального поведения: большое количество половых партнеров, постоянная реинфекция (отсутствие пролеченности от ИППП полового партнера), нетрадиционные способы секса, раннее начало половой жизни. Также, неправильное использование гигиенических и медикаментозных препаратов, чрезмерное использование антисептических средств, несоблюдение правил личной гигиены, неправильный и неконтролируемый прием антибиотиков, длительное и частое использование внутриматочных контрацептивов, наличие в анамнезе осложнений после медицинских абортов, родов, невынашивания, стрессовые ситуации. Кроме этого, асоциальный образ жизни: употребление наркотиков, курение, алкоголизм [8].

\section{Микрофлора влагалиша у женшин с ВЗОМТ}

У здоровых женщин репродуктивного возраста микрофлора влагалища включает аэробные, факультативно-анаэробные и облигатно-анаэробные виды микроорганизмов. У большинства женщин (50-90\%) микробиота влагалища представлена лактобациллами.
Оптимальная влагалищная микрофлора, как правило, существует симбиотически и защищает от колонизации и инфекции патогенными бактериями за счет производства молочной кислоты и побочных антимикробных продуктов, а также за счет активации иммунной системы. Доказано, что нарушение преобладания лактобацилл увеличивает риск инфекций, передаваемых половым путем (ИППП), и инфекций верхних отделов половых путей из-за распространения бактериальных патогенов и других анаэробных бактерий, которые в дальнейшем служат триггером в возникновении B3OMT [9].

Этиологическая структура ВЗОМТ многообразна, и каждое новое десятилетие вносит существенные коррективы во многие установившиеся представления о причинных факторах. Основными микроорганизмами, участвующими в возникновении воспалительных заболеваний органов малого таза являются следующие:

- Возбудители ИППП: Chlamidia trahomatis, Neisseria gonorrhoeae, Mycoplasma genitalium.

- Эндогенная микрофлора: Micoplasma hominis, Ureaplasma urealyticum.

- Анаэробные бактерии: Bacteroides spp., Peptostreptococcus spp., Prevotella spp.

- Аэробные бактерии: Escherichia coli, Gardnerella vaginalis, Haemophilus influenzae, Streptococcus spp., Staphylococcus spp. [10].

Характерной особенностью ВЗОМТ на современном этапе является возрастание условно-патогенной микрофлоры, из которых ведущая роль принадлежит E.coli. B тех случаях, когда E.coli является возбудителем абсцесса придатков матки, то заболевание зачастую протекает с признаками пельвиоперитонита. Также, важна ее роль в этиологии послеродовых и послеабортных осложнений. Кроме этого, особое внимание уделяется микоплазмам. В воспалительных заболеваниях органов малого таза участвуют около 11 видов, большинство из которых являются условно-патогенными, способствуя развитию воспаления. Например, M.genitalium, M.hominis. Кроме бактерий, в возникновении ВЗОМТ значимую роль играют грибковые поражения и вирусы [11].

Кроме этого, следует отметить роль вульвовагинальных инфекций, которые способствуют развитию воспалительных заболеваний органов малого таза, бесплодия, угрозе прерывания беременности, преждевременных родов, распространению вирусных инфекций таких как: вируса простого герпеса, вируса папилломы человека, вируса иммунодефицита человека [12]. Среди инфекций лидирующее место отводится бактериальному вагинозу, который варьирует (7-68\%) в зависимости от разных факторов: региона, расовой при- 
надлежности, вторым по распространенности является вульвовагинальный кандидоз (30\%). По последним данным, около 75\% женщин хотя бы раз в жизни перенесли вульвовагинальный кандидоз, а 45\% отмечают более двух эпизодов. Что касается аэробного вагинита, то эта не так давно описанная инфекция. Его распространенность, по данным различных авторов составляет от 5 до 24\%. В настоящее время, очень часто встречаются микст-инфекции, среди которых лидером является сочетание бактериального вагиноза и вульвавагинального кандидоза [13].

\section{Роль ИППП в развитии ВЗОМТ}

На сегодняшний день большую роль ученые отводят ИППП в развитии воспалительных заболеваний органов малого таза. Инфекции, передаваемые половым путем, занимают одно из лидирующих мест в акушерско-гинекологической практике. Вагинальные инфекции влияют не только на качество жизни, но и могут вызвать серьезные последствия в виде преждевременного прерывания беременности, плацентарной недостаточности, задержки роста плода, послеродовых гнойно-воспалительных осложнений. Инфекции, передаваемые половым путем в настоящее время стали серьезной проблемой в здравоохранении, так как их прогрессирование приводит к неблагополучию населения [14].

Одним из ярких представителей микроорганизмов, вызывающих В3ОМТ является C.trachomatis. Это - грамотрицательная бактерия, которая поражает цилиндрический эпителий шейки матки, уретры и прямой кишки и является частой бактериальной причиной инфекций, передаваемых половым путем. Хламидийная инфекция связана с широким спектром патологий верхних отделов половых путей, от бессимптомного эндометрита до симптоматического сальпингита, перитонита, тубо-овариального абсцесса, синдрома Фитц-Хью-Кертиса, характеризующегося воспалением в околопеченочных капсулах. Данная инфекция способствует возникновению таких осложнений как, бесплодие, внематочная беременность, хроническая тазовая боль [15].

Более того, хламидийная инфекция может привести к акушерским осложнениям, включая хориоамнионит, преждевременные роды, послеродовые и неонатальные инфекции. На сегодняшний день, ученые всего мира пришли к выводу о том, что хламидийная инфекция является самой распространенной и быстро распространяемой [16]. Хламидии часто встречаются в ассоциациях с другими бактериями, что ухудшает течение инфекции, в том числе облегчает передачу ВИЧ - инфекции. Сочетание хламидий с гонококком встречается в $34 \%$ случаев, трихомонадами-31\%, гарднереллами-10\%, кандидами-9\%. В частности, среди пациенток с вялотекущими хроническими сальпингоофоритами у $87 \%$ возбудителями являются микробные ассоциации: хламидии и стафилококк- $25 \%$, хламидии и кишечная палочка-17\%, хламидии и уреаплазмы-12-18\%. По данным ВО3, C.trachomatis ежегодно поражает более 131 миллиона человек [17].

Обращаясь к статистическим материалам Министерства Здравоохранения РФ, в 2019 году акушерами-гинекологами было выявлено 12607 случаев заражения хламидийной инфекцией среди женщин. Самый большой показатель в Российской Федерации зарегистрирован в Приволожском федеральном округе-3611 случаев, в Центральном федеральном округе-2015, наименьший показатель составил в Северо-Кавказском федеральном округе-567 случаев [18].

Кроме этого, в возникновении ВЗОМТ играет роль Neisseria gonorrhoeae. Это очень старая инфекция, которую можно проследить в древней китайской, египетской, римской и греческой литературе, а также в Ветхом Завете Библии [19]. Термин гонорея впервые применил Гален известный древнеримский философ, медик. Намного позже, в 1879 году фрунцузский ученый Нейсер открыл эту бактерию, которая напоминала зерна кофе. В честь этого ученого бактерия вскоре и была названа. Из всех заболеваний ИППП она до сих пор остается одной из медико-социальных проблем общества. Neisseria gonorrhoeae-облигатный патоген, передающийся в первую очередь при половом акте [20]. Новорожденные могут заразиться во время прохождения через родовые пути, если у матери мочеполовая гонорея. После передачи, N. Gonorrhoeae вызывает уретрит у мужчин и цервицит у женщин. У большинства женщин (более 50\%) отмечается бессимптомная урогенитальная инфекция, которая при отсутствии лечения может распространяться в верхние отделы половых путей, вызывая воспалительные заболевания органов малого таза. Кроме этого, данная инфекция облегчает передачу и приобретение ВИЧ [21,22].

В настоящее время, по данным ВОЗ гонорейной инфекцией страдают 78 миллионов человек [23]. В нашей стране, по официальным статистическим данным, 12833 человека инфицированы [24]. В ЦФО-1441. Самый большой показатель заболеваемости гонорейной инфекцией в Дальневосточном федеральном округе-2605, самый наименьший в Южном федеральном округе-851.

\section{$\triangle$ иагностика воспалительных заболеваний органов малого таза}

Диагностика базируется на клинических, микробиологических и лапароскопических данных, дополненных морфологическими исследованиями [25]. Клиническая диагностика ВЗОМТ зачастую неточна, а клиническая 
картина многообразна. Диагностика воспалительных заболеваний органов малого таза в настоящее время представляет сложность, так как многие симптомы одинаковые. К характерным жалобам пациенток с В3ОМТ относят боли в нижней части живота, кровянистые, сукровично-гнойные, гноевидные выделения, также нарушения менструального цикла. Кроме этого может отмечаться нарушение работы соседних органов и систем (мочевыделительной и ЖКТ), лейкоцитоз, повышение температуры тела, повышение СРБ, лабораторное подтверждение инфекций [26].

В настоящее время разрабатываются новые способы диагностики ИППП. В нашей стране диагностика ИППП, в основном, осуществляется методом ПЦР (Полимеразная цепная реакция). Ряд стран разрабатывает новые методики выявления инфекций. В частности, в Калифорнии разработан ряд тестов РОС (диагностика рядом с пациентом). Например, тест binx health io CT / NG (binx health, Inc) - это быстрая качественная диагностическая система на основе ПЦР, состоящая из небольшого настольного полностью интегрированного прибора, в котором используются одноразовые картриджи для конкретных анализов [27]. Образцы пациента загружаются непосредственно в картридж, и подготовка образцов не требуется. Время от ввода образца пациента до получения результата составляет около 30 минут. Тест имеет маркировку CE и получил разрешение FDA в августе 2019 года для использования в образцах вагинальных мазков. В на- стоящее время разрабатывается ряд многообещающих диагностических тестов POC. В таком тесте mobiNAAT представляет собой NAAT (тест ампликации нуклеиновых кислот) на базе мобильного телефона, в котором используется магнитожидкостный картридж размером с USB-yстройство для выполнения изотермического усиления с опосредованной петлей, которое питается и управляется через мобильный телефон. Платформа дает результаты примерно за 1 час. Прототип устройства для тестирования на C.trachomatis был оценен в условиях отделения неотложной помощи, и результаты показали $100 \%$ соответствие стандарту лечения NAAT [28].

\section{Зак^ючение}

Для предотвращения увеличения численности заболеваемостью ВЗОМТ необходимо проводить просветительскую работу среди населения. Повышать информированность населения и прежде всего лиц, относящихся к группам риска, о заболеваниях, передаваемых половым путем, и их последствиях. Прежде всего, это скрининговые исследования, которые являются неотъемлемой частью в выявлении ИППП. Но, сложность заключается в том, что на сегодняшний день люди боятся проходить анкетирование, обращаться с существующими инфекциями к врачам, так как большинство боится социального осуждения и дискриминации. Необходимо проводить беседы по гигиенической профилактике ИППП среди населения.

\section{ЛИТЕРАТУРА}

1. Авраменко Н.В. Воспалительные заболевания органов малого таза у женщин как ведущий фактор формирования трубно-перитонеального бесплодия / Н.В. Авраменко // Запорожский медицинский журнал - 2014- № 4(85) - С. 63-68

2. Прилепская В.Н., Сехин С.В. Воспалительные заболевания органов малого таза: диагностика и тактика ведения больных / В.Н. Прилепская., С.В. Сехин // Российский вестник акушера-гинеколога - 2015 — № 4-C. 101-106

3. Зароченцева Н.В. Воспалительные заболевания органов малого таза у женщин (обзор литературы) / Н.В. Зароченцева, А.К. Аршакян, Н.С. Меньшикова // Гинекология. - 2013 - Т. 15. — № 4. - С. 65-69

4. Нургалиева Е.В., Духин А.О., Гущин А.Е. Микробиота женских половых органов при гнойно-воспалительных заболеваниях гениталий / Е.В. Нургалиева, А.О. Духин, А.Е. Гущин // Вестник РУДН. Серия: Медицина — 2016 — № 2 - С. 197-201

5. Уткин Е.В., Кулавский В.А. Воспалительные заболевания органов малого таза у женщин. Учебное пособие. Кемерово, 2014. - 36 с.

6. Ross J. Pelvic inflammatory disease / J. Ross // BMJ Clin. Evid._- 2013-Vol.12, № 1606.—P.1-28

7. The British Association for Sexual Health and HIV (BASHH). Pelvic inflammatory disease. Guideline. 2019.

8. Workowski K.A., Bachmann L.H., Chan P.A. Sexually Transmitted Infections Treatment Guidelines / K.A. Workowski, L.H. Bachmann., P.A. Chan // MMWR Recomm Rep-2021;70(No.RR-4)-P.1-187

9. Довлетханова Э.Р. Современные направления терапии генитальных инфекций и бактериального вагиноза/ Э.Р. Довлетханова // Эффективная фармакотерапия - 2015 - № $25-$ C. $48-51$

10. Акушерство и гинекология. Клинические рекомендации, 4-е издание переаботанное и дополненное / под ред. Г.М. Савельевой, В.Н. Серова, Г.Т. Сухих.-М.: ГЭОТАР — Медиа, 2019.- 1200 с.;

11. Уткин Е.В. Воспалительные заболевания органов малого таза у женщин: Современные особенности клиники, диагностики и терапии / Е.В. Уткин // Мать и дитя в Кузбассе - 2009 - № 3 (38) - С. 9-15.

12. Савичева А.М., Спасибова Е.В., Шипицына Е.В., Воробьёва Н.Е., Переверзева Н.А., Бриль Ю.А. Вагинальный микробиом: перезагрузка представлений / А.М. Савичева, Е.В. Спасибова, Е.В. Шипицына, Н.Е. Воробьева, Н.А. Переверзева, Ю.А. Бриль // StatusPraesens. Гинекология, акушерство, бесплодный брак- 2018- № 3 (47) - C. 51-59. 
13. Савичева А.М., Тапильская Н.И., Шипицына Е.В., Воробьева Н.Е. Бактериальный вагиноз и аэробный вагинит как основные нарушения баланса вагинальной микрофлоры. Особенности диагностики и терапии / А.М. Савичева, Н.И. Тапильская, Е.В. Шипицына, Н.Е. Воробьева // Акушерство и гинекология - 2017 - № 5 - С. 24-31.

14. STATUS PRAESENS. Гинекология, акушерство, бесплодный брак № 5 (61)-2019- С. 7-9.

15. Довлетханова Э.Р. Воспалительные заболевания органов малого таза (роль ИППП в развитии ВЗОМТ) / Э.Р. Довлетханова // Медицинский Совет 2013 - № 8 - С. $62-65$

16. Дубровина С.О. Роль хламидий в этиологии воспалительных заболеваний органов малого таза / С.О. Дубровина // Акушерство и гинекология 2017 - № 2-C. 119-124

17. https://apps.who.int/mediacentre/news/releases/2016/antibiotics-sexual-infections/ru/index.html

18. Социально значимые заболевания населения России в 2018 году (Статистические материалы). Москва 2019.

19. Национальное руководство гинекология под руководством Савельевой Г.М., Сухих Г.Т., Серова В.Н., Радзинского В.Е., Манухина И.Б.2017.

20. Инфекционные болезни и эпидемиология: Учебник / В.И. Покровский, С.Г. Пак, Н.И. Брико, Б.К. Данилкин.— 2-е изд.- М.: ГЭ0ТАР-Медиа, 2007.C. 816

21. Глобальная стратегия сектора здравоохранения по инфекциям, передаваемым половым путем на 2016-2021 гг.: на пути к ликвидации ИППП.

22. Unemo. M., Seifert. H.S., Hook. E.W. et al. Gonorrhoea / M. Unemo., H.S. Seifert., E.W. Hook. // Nat Rev Dis Primers — 2019- Vol.5, № 79.

23. https://www.who.int/ru/news-room/fact-sheets/detail/multi-drug-resistant-gonorrhoea

24. Заболеваемость, инвалидность и состояние здравоохранения в странах Содружества. Москва,2019.

25. Подзолкова, Н.М. Симптом, синдром, диагноз. Дифференциальная диагностика в гинекологии [Текст] / Н.М. Подзолкова, 0.Л. Глазкова. - М.: ГЭ0ТАР-Медиа, 2014.- С. 736

26. Сенчукова С.Р., Пичигина А.К., Молодых 0.П. Этиологическая структура воспалительных заболеваний органов малого таза у женщин фертильного возраста в современных условиях. Современные проблемы науки и образования 2018; 5; URL: https://science-education.ru/ru/article/view?id=28093 (дата обращения 04.11.2021)

27. Adamson P.C., Loeffelholz M.J., Klausner J.D. Point-Of-Care testing for sexually transmitted infections: a review of recent developments /P. C. Adamson, M.J. Loeffelholz, J.D. Klausner // Arch Pathol Lab Med -2020-144:1344-51.10.5858

28. Harding-Esch E.M., Cousins E.C., Chow S.L. A 30-min nucleic acid amplification point-of-care test for genital chlamydia trachomatis infection in women: a prospective, multi-center study of diagnostic accuracy / E.M. Harding-Esch, E.C. Cousins, S.L. Chow // EBioMedicine- 2018; 28-P.120-127.

( Л Лещева Мария Юрьевна ( pantera7695@mail.ru ),Коротких Ирина Николаевна ( korotkih_1950@mail.ru ).

Журнал «Современная наука: актуальные проблемы теории и практики» 